\title{
James Hutton e o Sublime Geológico: a Teoria da Terra entre o lluminismo e o Romantismo
}

\author{
James Hutton and the Geological Sublime: the Theory of the Earth at the crossroads between Enlightenment and Romanticism
}

\author{
Fabrício de Andrade Caxito
}

Depto. Geologia e C. Pesq. Manoel Teixeira da Costa, Inst. Geoc., Univ. Fed. Minas Gerais, Av. Antônio Carlos 6627, Pampulha, 31270901 Belo

Horizonte, MG. - caxito@ufmg.br.

ABSTRACT: The works of the Scottish geologist, naturalist and physicist James Hutton (1726-1797), in the context of the Scottish Enlightenment, were greatly influenced by the ideas of intellectuals such as Isaac Newton and David Hume, representing a synthesis and a transposition of the moving force of Enlightenment to the newborn Earth sciences. His view of the terrible magnitude of natural forces and the immense amounts of geological time as compared to the briefness of human life reflects the Kantian concepts of Dynamic and Mathematic Sublime, respectively. From the development of geology as a science which opened the human eye to natural history, it is possible to draw a parallel between the theories of James Hutton and the views about Nature of the romantic poets of the XIX century, mainly Coleridge and Wordsworth. In this way, geology is born as a Science exactly at the crossroads between two of the main intellectual and cultural movements of Western civilization, Enlightenment and Romanticism.
Manuscrito:

Recebido: 24/04/2017

Corrigido: 08/09/2017

Aceito: 26/09/2017

Citation: Caxito F. A. 2017. James Hutton e o Sublime Geológico: a Teoria da Terra entre 0 lluminismo e o Romantismo. Terræ Didatica, 13(3):235-243. $<$ http://www.ige.unicamp.br/terraedidatica/>.

Keywords: James Hutton, Theory of the Earth, Enlightenment, Romanticism

\section{Introdução}

\begin{abstract}
"We have now got to the end of our reasoning (...) we have the satisfaction to find, that in nature there is wisdom, system, and consistency. For having, in the natural history of this earth, seen a succession of worlds, we may from this conclude that there is a system in nature; in like manner as, from seeing revolutions of the planets, it is concluded, that there is a system by which they are intended to continue those revolutions. But if the succession of worlds is established in the system of nature, it is in vain to look for anything higher in the origin of the earth. The result, therefore, of our present enquiry is, that we find no vestige of a beginning, - no prospect of an end."
\end{abstract}

Hutton, J. 1788. Theory of the Earth; or an investigation of the laws observable in the composition, dissolution, and restoration of land upon the Globe. Transactions of the Royal Society of Edinburgh, vol. 1, Part 2, p. 304.

"The mind seemed to grow giddy by looking so far back into the abyss of time..."

Palavras pronunciadas por John Playfair sobre a famosa discordância de Siccar Point, Escócia, apresentada a ele por Hutton em 1788.
As palavras acima, retiradas das comunicações do geólogo, médico, químico e naturalista escocês James Hutton [1726-1797] para a Sociedade Real de Edimburgo em 1788, e a reação de seu amigo John Playfair ao conhecer as evidências de campo que o levaram até tais conclusões, resumem a perplexidade dos cientistas naturais setecentistas ao encarar pela primeira vez a infinitude do tempo geológico, um tempo muitíssimo mais longo do que o que era então previsto, baseado em interpretações escolásticas da Bíblia e outros escritos sagrados (p. ex. Ussher 1658), e que seria necessário para que pudessem tomar forma os ciclos de formação, erosão e reciclagem das rochas da crosta terrestre, seus fósseis e minerais, como observado por Hutton, Steno, e muitos outros naturalistas.

James Hutton foi figura central no chamado Iluminismo Escocês. Junto com Joseph Black e Adam Smith, foi um dos fundadores do Oyster Club, um clube de intelectuais cujos membros e visitantes célebres incluíam ninguém menos do que David Hume, James Watt e Benjamim Franklin (Tomkeieff 1949, Furniss 2010). Como veremos, o Princípio de Uniformidade da Natureza de Hume (1777) foi muito importante para que James Hut- 
ton desenvolvesse sua própria visão uniformitarista dos processos naturais.

\section{Uma breve história da visão humana sobre 0 Tempo Geológico}

Aristóteles, o famoso filósofo grego que viveu no século IV A.C., era dotado de enorme senso de observação do mundo natural, para o qual propôs diversas classificações e subdivisões. Também na geologia ele deu suas contribuições: antecipando as observações que só seriam sistematizadas séculos depois, ele propôs que os sistemas naturais estão em constante e lenta mudança, uma mudança que não pode ser detectada no ciclo de vida de um indivíduo apenas. Em seu Principles of Geology, Charles Lyell $(1832$, p. 21) cita o livro XII da Meteórica de Aristóteles (tradução livre):

"A distribuição da terra e do mar em regiões particulares não dura por todo o tempo, mas aquelas partes que eram terra se tornam mar, e de novo onde era mar se torna terra, e há razão para pensar que essas mudanças ocorrem de acordo com um certo sistema, e durante um certo período. (...) Como o tempo nunca falha, e o universo é eterno, nem o Tánais, nem o Nilo, podem ter fluido para sempre. Os lugares onde eles nascem eram antes secos, e há um limite para suas operações, mas nenhum limite para o tempo. Isso também para os outros rios: eles nascem e morrem; e o mar também continuamente torna algumas terras desertas enquanto invade outras. Os mesmos tratos, então, da Terra não são sempre mar, e outros sempre continentes, mas tudo muda no curso do tempo."

Por meio desta citação podemos observar que Aristóteles acreditava que o universo, e consequentemente o planeta Terra em que vivemos, é eterno, uma ideia que ele desenvolve principalmente no livro VIII de sua Física. A ideia de um tempo linear (com começo, meio e fim) em contradição com o tempo cíclico de Aristóteles, porém, começa a ganhar força já no século IV AC com Epicuro, e posteriormente com o grande defensor do epicurismo, o poeta latino Lucrécio, que viveu no século I AC. Este último, em seu poema De rerum natura $(\mathrm{Da}$ natureza das coisas) desenvolve teorias interessantes, como a de que a luz é feita de pequenas partículas (antecipando em milênios o conceito de fótons) e da existência de criaturas microscópicas que, apesar de invisíveis, poderiam causar doenças (antecipando a microbiologia). Ao contrário da crença no eterno de Aristóteles, Lucrécio observa que a formação da Terra deve ter sido recente, porque não eram conhecidos registros anteriores à Guerra de Tróia (que provavelmente ocorreu entre 1300 e $1200 \mathrm{AC}$ ).

Durante a Idade Média e o Renascimento, as tentativas de se estimar a idade da Terra baseavam-se principalmente em textos religiosos, por meio da extrapolação para trás no tempo, contando as diversas gerações narradas no registro bíblico. Os rabinos talmúdicos, assim como Martinho Lutero e outros religiosos, ofereceram diversas estimativas desse tipo. A mais famosa de todas veio do arcebispo irlandês James Ussher, que no livro The Annals of the World (1658) concluiu que a criação do mundo ocorreu no dia 23 de outubro de 4004 A.C., o que lhe conferiria cerca de 6.000 anos de idade.

Apesar de à época, e por muito tempo, essa afirmação ter sido amplamente aceita, aqueles que observavam e conheciam as mudanças do planeta já desconfiavam seriamente de que a estimativa era muito baixa. Era preciso muito mais tempo para que as rochas pudessem se formar e modificar na superfície terrestre. Em outubro de 1666, dois pescadores capturaram um enorme tubarão próximo à cidade de Livorno, na atual Itália, e o grão-duque Fernando II de Médici mandou enviar a cabeça da presa para o seu protegido Nicolau Steno, na época um famoso médico anatomista e bispo dinamarquês convertido ao catolicismo após ter ser criado em uma casa luterana. Steno dissecou e analisou pormenorizadamente a cabeça do tubarão, e notou que os seus dentes eram muito semelhantes a objetos encontrados em rochas, conhecidos como glossopetrae ou pedras-língua. A explicação para a ocorrência dessas pedras-língua era controversa: Plínio, o Velho, achava que elas haviam caído do céu em noites de Lua; outros eram da opinião que elas cresciam naturalmente nas rochas. Athanasius Kirchner, contemporâneo de Steno, falava de uma "virtude lapidificante dispersa pelo geocosmo". Steno foi o primeiro a apresentar formalmente a interpretação mais adequada: as glossopetrae se parecem com dentes de tubarão porque são de fato dentes fósseis de tubarão, soterrados por lama e terra que após a deposição haviam se solidificado.

O que por si só já foi uma descoberta extraordinária colocou Steno em uma senda nunca antes trilhada, que acabou por levar à formulação dos princípios básicos de estratigrafia hoje ensinados em todas as escolas de geologia do mundo. Steno ficou fascinado pela forma como um corpo sólido pode ocorrer dentro de outro corpo sólido na natureza, e pelas relações de corte e sobreposição entre estes 
corpos. Estendeu o seu estudo sobre os fósseis para englobar também cristais, incrustações, veios, e até mesmo camadas inteiras de rochas. Seu trabalho foi publicado em De solido intra solidum naturaliter contento dissertationis prodromus (1969), em uma tradução livre, Discurso prévio a uma dissertação sobre um corpo sólido contido naturalmente em outro sólido.

Contemporâneos de Steno, os cientistas ingleses John Ray e Robert Hooke defenderam ideias semelhantes sobre a origem dos fósseis. Com o avanço dos estudos e do reconhecimento dos fósseis, Hooke chegou a sugerir que o registro fóssil requeria um tempo muito maior do que o proposto pela estimativa de Ussher e de outros religiosos. Estavam lançadas as pedras fundamentais do pensamento racionalista que levou a uma nova visão sobre a idade da Terra e como deveriam ser feitas as tentativas de sua estimativa.

\section{A Teoria da Terra de James Hutton - uma forte influência de David Hume, Isaac Newton e até mesmo Heráclito}

Neste contexto é que James Hutton irá apresentará suas ideias à Sociedade Real de Edimburgo, na primavera de 1785 , publicadas logo em seguida como "Abstract of a Dissertation Read in the Royal Society of Edinburgh ... Concerning the System of the Earth, its Duration, and Stability." (Hutton 1785; apud Craig 1987). A comunicação foi bastante criticada, principalmente em bases religiosas, por não apresentar evidências empíricas suficientes que pudessem comprovar as ideias ali apresentadas. Hutton então embarca para uma série de viagens de campo na Escócia em busca das evidências empíricas (Baxter 2004). Em 1788 adicionaria os dados de campo a uma versão revisada do seu artigo, no primeiro volume de Transactions of the Royal Society of Edinburgh sob o título "Theory of the Earth; or an investigation of the Laws Observable in the Composition, Dissolution, and Restoration of Land upon the Globe" (Hutton, 1788), e em 1795, pouco tempo antes da sua morte, nos primeiros dois volumes de Theory of the Earth, with Proofs and Illustrations (Hutton 1795), onde apresenta uma grande quantidade de dados que dariam suporte à sua teoria.

À época de Hutton, existiam duas teorias principais em voga entre os cientistas naturais para explicar a distribuição das rochas na superfície terrestre (Tomkeieff 1949). A visão dominante era a do chamado Netunismo, cujo principal defensor era Abraham Gottlob Werner (por isso, chamado às vezes de Wernerismo), que dizia que a superfície da Terra foi formada e sua topografia foi definida por um dilúvio ou por uma série de dilúvios (Montgomery 2017), uma teoria que obviamente encontrava grande suporte nos meios religiosos por sua fácil adaptação ao relato bíblico de Noé. Esta teoria se baseava em algumas evidências empíricas, como por exemplo a ocorrência de fósseis marinhos em cadeias de montanhas atuais, como os Alpes. A principal teoria concorrente era a do Vulcanismo, que dizia que pelo menos parte das feições da superfície terrestre atuais eram originárias de atividade vulcânica.

Hutton aceitava a ideia que os estratos rochosos haviam sido depositados por meio da acumulação de materiais detríticos e fósseis no fundo dos oceanos, mas tinha uma visão oposta quanto ao agente consolidador das rochas. Para Hutton, este agente não seria a água em si, mas sim o calor e a pressão provenientes das profundezas terrestres. Este era um argumento também válido empiricamente de acordo com as experiências dos mineradores de carvão nas ilhas britânicas na época: quanto mais fundo se cavava, mais quente era a sensação térmica dentro das minas (num gradiente geotermal entre $25 \mathrm{e} 40^{\circ} \mathrm{C}$ por $\mathrm{km}$ ). Hutton inovou ao interpretar rochas de granulação grossa (granitos e gabros, por exemplo) como correspondentes às rochas vulcânicas, isto é, vindas da consolidação de um magma (rocha fundida), porém cristalizadas em profundidade, onde o calor era mais alto e o tempo de cristalização das rochas era maior. Desta forma, muitas vezes Hutton é considerado como um representante do Plutonismo, e estas rochas conhecidas como rochas plutônicas, em referência à Plutão. As rochas ígneas (plutônicas, se cristalizadas em uma câmara magmática em profundidade, e vulcânicas, se cristalizadas a partir do magma que extravasa na superfície terrestre) seriam as rochas primordiais a partir das quais os outros tipos de feições da superfície terrestre se formariam.

De forma bastante contundente, Hutton rejeitou as visões catastrofísticas, segundo as quais as feições da superfície terrestre teriam sido formadas quase instantaneamente em eventos catastróficos que ocorreram no passado e que não mais ocorrem (por exemplo, um grande dilúvio). Ao invés disto, Hutton formulou que todas as feições geomorfológicas e geológicas são o resultado da ação lenta e regular de forças naturais em escalas de tempo muito vastas (vide discussão em Gould 1991). Por isto, sua teoria é conhecida como Uniformitarista: 
Processos que ocorrem na natureza hoje devem ter ocorrido de forma similar no passado. Neste sentido, percebe-se a clara influência de David Hume dentro do fenômeno do Iluminismo Escocês.

David Hume (1777) define que todo o conhecimento humano provém de ideias e impressões, mas que na verdade as ideias são construídas a partir das impressões que temos do mundo, conectando-as por meio dos processos de semelhança, contiguidade e causalidade. Especialmente o princípio da causalidade é muito importante para a construção do conhecimento humano, ao fornecer uma base para a resolução das questões de fato não presentes, isto é, aquelas questões em que não é possível conferir, a posteriori, a veracidade ou não da afirmação. Neste caso fundamentamos nosso conhecimento no princípio de causa e efeito, baseado nas experiências que acumulamos. Este processo é chamado de inferência indutiva, onde a partir de experiências passadas ou presentes, tentamos inferir uma conclusão geral preditiva. Hume notou, porém, que os argumentos baseados em inferências indutivas fornecem apenas conclusões contingentes. Isto quer dizer que, mesmo que as premissas (nossas experiências passadas) sejam verdadeiras, há sempre a possibilidade da conclusão (nossa predição para o futuro ou nossa tentativa de generalização) seja falsa. Esta última consideração tem um enorme impacto para a estrutura do conhecimento científico, já que grande parte da ciência se baseia em inferências indutivas para construir leis pretensamente gerais sobre o funcionamento do cosmos.

Hume tenta resolver essa questão ao introduzir o Princípio de Uniformidade da Natureza. Este princípio é intercalado após as premissas para fornecer uma maior validade à conclusão. Por exemplo, se observamos no passado que todo animal morre (premissa 1) e no presente que todo animal continua a morrer (premissa 2) podemos intercalar o Princípio de Uniformidade da Natureza (A Natureza mantém sua uniformidade no tempo) para chegar à conclusão que todos os animais são mortais. Essa estrutura argumentativa foi, posteriormente, sintetizada e vulgarizada por diversos autores no ramo das ciências geológicas e naturais por meio do lema "O presente é a chave para o passado". Hume, porém, atinge uma posição cética ao apontar que o próprio Princípio de Uniformidade da Natureza é baseado num raciocínio indutivo - portanto, embora válido, não necessariamente verdadeiro. É a propensão humana em enxergar regularidades e causalidade no mundo natural que nos faz prestar enorme adesão aos raciocínios indutivos, embora não haja garantias racionais para que este tipo de raciocínio conduza a conclusões necessariamente verdadeiras.

Aplicando então o Princípio de Uniformidade da Natureza às feições geológicas, Hutton formula que os processos que hoje podemos observar em atuação (por exemplo, a erosão de grandes cadeias de montanhas e o transporte de seus detritos por rios até o oceano, ou a atividade vulcânica) são os mesmos processos que atuaram no passado no planeta (e às mesmas taxas). Os dois princípios que formam a base do Uniformitarismo são o Atualismo (as forças da natureza hoje são idênticas às do passado) e o Gradualismo (as mudanças ocorrem de forma lenta e gradual, não catastrófica).

Como apontado por Stephen Jay Gould em seu livro "Seta do Tempo, Ciclo do Tempo" (Gould 1991), a teoria da Terra de Hutton é baseada num modelo cíclico de tempo calcado nos princípios Newtonianos, principalmente a analogia com o funcionamento do Sistema Solar. Hutton se apresenta como um fiel seguidor dos princípios Newtonianos, sem forjar hipóteses e apenas chegando às conclusões após a análise cuidadosa das evidências (Furniss 2010). É interessante notar como o aspecto dinâmico da geologia apresentado por Hutton representa uma aplicação do aspecto dinâmico da natureza já apresentado por Galileu, Newton e Leibniz. A continuidade matemática do Cálculo de Newton e Leibniz fornece uma base através da qual a integração de uma multitude de pequenos valores leva a grandes mudanças no todo. Este princípio de integração, ao ser aplicado para o sistema Terra, negaria a teoria geológica então prevalecente do catastrofismo, e introduziria um novo princípio segundo o qual a interação de múltiplos pequenos processos naturais levaria à forma do todo terrestre como podemos observar naturalmente.

A princípio Hutton aparece como um deísta clássico, compromissado com a visão de que a beleza e a complexidade dos sistemas terrestres aparecem como testemunho da força de um ser superior. Por exemplo, na página 209 de Hutton (1788), “o todo apresenta uma máquina de peculiar construção por intermédio da qual é adaptada para um fim peculiar" (tradução livre) - este fim seria o suporte da vida sobre a Terra, e como explicitado na linha 213, "(os poderes naturais) não podem ser considerados inúteis em uma máquina construída certamente não sem sabedoria". Porém, à medida que avança em sua exposição, uma visão diferente vai se apresentando, com a Terra se parecendo cada vez mais com um 
organismo vivo formado por diversos sistemas complexos, e a Natureza como um ser sensível com seus próprios poderes criativos e transformadores, o que já acontece na mesma página: “... não vamos procurar a natureza em um estado quiescente; a matéria por si só deve estar em movimento, e as cenas da vida uma contínua ou repetida série de agitações e eventos". Para entender essa visão do planeta é interessante considerarmos que a tese doutoral de Hutton, defendida em Leiden (Hutton 1749), é sobre a circulação do sangue no corpo humano; nada mais natural que ele procurasse o mesmo tipo de relações sistema-todo no mundo natural.

Hutton parte então para um delineamento dos principais poderes naturais por meio dos quais esse movimento eterno poderia ser produzido. Ele começa com uma base fortemente Newtoniana, dizendo que a Terra é mantida em sua órbita pelo equilíbrio de duas forças - o seu momento no espaço e a força gravitacional do Sol (Hutton 1785, p. 213). Os movimentos da Terra ao redor do seu eixo e ao redor do Sol produzidos por estas duas forças geram então ciclos diuturnos de calor e frio, luz e escuridão, que por sua vez irão produzir outros efeitos, que poderão ser chamados de "forças" naturais em seu próprio mérito. Esta visão de uma Terra ativa, delineada por um conjunto de forças vitais, levou alguns autores a afirmar que na verdade Hutton acabou por rejeitar completamente a visão Newtoniana durante a sua exposição (p. ex. Piper 1962). Isto se deve em parte a uma interpretação errônea de Newton, principalmente por parte dos românticos ingleses (p. ex. Blake e Keats) que enxergavam uma suposta oposição entre o mecanicismo Newtoniano e o vitalismo romântico (Furniss 2010). De qualquer forma, a visão Newtoniana de que forças ativas moldam o mundo natural foi aplicada com sucesso por Hutton para explicar um Sistema Terra em contínua atividade, numa época em que muitos geólogos ainda entediam os princípios Newtonianos como balizadores da visão de uma Terra estática e passiva (Porter 1977).

Talvez como um reflexo de seu passado como médico, uma parte importante da teoria de Hutton consiste na divisão dos sistemas terrestres em três corpos distintos, porém inter-relacionados: um corpo sólido de terra, um corpo aquoso de mar, e um fluído elástico de ar (Hutton 1785, p. 211). As inter-relações entre estes três corpos compõe a base da sua Teoria da Terra, onde o planeta se parece cada vez mais com um corpo orgânico massivo que funciona como um coletivo macrocósmico dos diversos microcosmos que abriga (plantas, animais, etc.).
É neste ponto que Hutton apresenta a sua oposição a uma visão de tempo uniformemente linear, como proposto nas interpretações bíblicas do tempo geológico à época. Se assumirmos um tempo linear e progressista, paradoxalmente os sistemas circulatórios do ar e da água que sustentam a vida na Terra levariam à própria destruição do sistema, pois, pela atuação destes dois sistemas na erosão das cadeias de montanhas:

"As alturas de nossa terra são então niveladas com as costas; nossas planícies férteis são formadas pelas ruínas das montanhas; e estes materiais viajantes são perseguidos pela água corrente, e impelidos através da superfície inclinada da Terra. Estes materiais móveis são entregues ao mar... e levados cada vez mais longe nas suas profundezas..." (Hutton 1785, p. 215,).

Depois de certo (imenso) tempo, Hutton afirma então que toda a Terra seria completamente erodida e não haveria mais propósito para a máquina. Hutton previu então que deveria haver algum processo natural, ainda não conhecido, que restauraria as terras altas para permitir que a Terra continuasse o seu eterno movimento em prol do objetivo final a sustentação da vida. Neste ponto uma profunda virada ocorre em sua argumentação. Se não existe um poder reprodutivo ou reformador capaz de restaurar a terra perdida pela erosão, "nós teríamos razão para concluir, que o sistema da terra ou foi feito intencionalmente para ser imperfeito, ou que não é fruto do trabalho de um poder e sabedoria infinitos" (Hutton, 1785, p. 216). Como Hutton não se sente propenso a abandonar sua visão deísta, ele modifica a analogia inicial da seguinte maneira:

"Mas este mundo deve ser considerado apenas como uma máquina, que não irá durar mais do que as suas partes (...)? Ou ele não poderia também ser considerado como um corpo organizado? E desta forma possui uma constituição tal que o necessário decaimento da máquina é naturalmente reparado..." (Hutton 1785, p. 216).

Hutton então rejeita a noção de um deus ex machina que constantemente atua para miraculosamente reparar o sistema terra, em prol de uma Terra viva como um corpo orgânico, que possui a capacidade e o poder de restaurar a si mesma. O "processo de restauração" de Hutton passa por dois momentos. Primeiro, é preciso haver a consolidação dos detritos rochosos das cadeias de montanhas, levados pelos rios até o fundo dos oceanos, em novas rochas. Hutton aplica então noções de química básica para provar que somente a ação da água não seria sufi- 
ciente para gerar a quantidade de tipos rochosos que hoje encontramos na superfície da Terra. Ele propõe que as rochas se formam pela ação de pressão e temperatura, quando os detritos são soterrados a profundidades suficientemente grandes para que haja a formação de magma a partir de suas fusões, cujo resfriamento e cristalização originará novas rochas. Hutton afirma então que "Todo estrato sólido do globo foi condensado por meios de calor, e endurecido a partir de um estado de fusão" (p. 259-60); a base da visão Plutonista. Porém, embora Hutton estivesse correto em dizer que a pressão e o calor são os principais agentes formadores de rochas ígneas e metamórficas, hoje sabemos que ele estava errado em rejeitar o papel da água na deposição de algumas rochas sedimentares, por exemplo os calcários, que se depositam por meio da precipitação direta dos íons $\mathrm{Ca}^{2+} \mathrm{e} \mathrm{CO}^{3-}$ da água do mar. De qualquer forma, a visão Plutonista ajudou a deslocar a importância da então prevalecente visão Netunista.

O segundo momento do processo de restauração envolve o soerguimento das novas rochas, recém-formadas, acima do nível dos oceanos, onde elas formariam novas cadeias de montanhas. Neste sentido, Hutton nota que "não há nada tão propenso para o soerguimento da terra acima do nível do oceano, como um poder expansivo de suficiente força, aplicado diretamente sob os materiais no fundo do mar" (Hutton 1785, p. 262). Sem o benefício de poder contar com a teoria moderna de tectônica de placas do século XX, Hutton foi capaz de deduzir que o principal agente para o soerguimento da crosta terrestre é o calor subterrâneo, como nota na página 266: "O poder do calor para a expansão dos corpos é, até onde sabemos, ilimitado". Esta expansão também explicaria o dobramento e fraturamento das rochas observado comumente em cadeias de montanhas. A teoria de Hutton traz então aspectos revolucionários sobre o funcionamento interno do planeta: o seu núcleo supostamente inerte e sólido seria a fonte daquele poder caloroso que consolida e soergue os novos materiais acima do nível dos oceanos, em eterna oposição às forças que atuam na superfície terrestre em busca da erosão e nivelamento das massas soerguidas. Hutton traz uma revolução na visão do planeta, que deixa de ser visto como um corpo sólido e inerte e se mostra agora como um organismo vivo e pulsante, em constante movimento circulatório, possivelmente o mais importante conceito da geologia moderna (Craig 1987).

A visão de Hutton de uma Terra em eterno fluxo e em eterno movimento entre um estado e outro, com forças atuantes no sentido do soerguimento das massas terrestres sendo constantemente balanceadas por forças atuantes no sentido oposto, de erosão das massas, remete-nos aos conceitos de Heráclito, pensador pré-socrático que enfatizava o eterno fluxo do universo, como no fragmento DK 22 b 30: "Este mundo, o mesmo de todos os (seres), nenhum deus, nenhum homem o fez, mas era, é e será um fogo sempre vivo, acendendo-se em medidas e apagando-se em medidas".

\section{O Sublime Geológico: Relações entre Burke, Kant e Hutton}

À época de sua apresentação, as ideias de Hutton não receberam acolhida muito calorosa da comunidade científica em geral, chegando a ser mesmo duramente criticadas. Isto é devido em parte ao clima geral na Europa na esteira da Revolução Francesa, já que a data de lançamento de Teoria da Terra coincidiria com uma época bastante propícia à caça de heréticos, principalmente nas ilhas britânicas (Tomkeieff 1949). Mas a recepção fria de suas ideias deve também bastante ao estilo conhecidamente árduo e espinhoso dos escritos de Hutton. O reconhecimento tardio da importância de seu trabalho deve-se principalmente à divulgação de suas ideias por Charles Lyell, autor do livro-texto clássico Principles of Geology, nascido no ano da morte de Hutton. Lyell, por sua vez, adquiriu conhecimento das ideias revolucionárias huttonianas por meio do amigo próximo de Hutton e seu "tradutor" para a comunidade científica, John Playfair. A tradução das ideias de Hutton efetuada por Playfair (1802) se explicita na citação poética na epígrafe deste artigo, que resume a sensação de pequenez da mente humana ao ser confrontada pela primeira vez, com bases científicas, com um tempo geológico imensamente maior do que a sua capacidade de compreensão.

Hutton descreve a agora famosa discordância de Siccar Point, Escócia, onde pôde perceber uma evidência de campo para suas ideias de tempo cíclico na geologia. Uma discordância é uma antiga superfície erosiva onde camadas geológicas mais antigas, que muitas vezes já sofreram um ciclo de soerguimento, dobramento e erosão, são superpostas por camadas mais novas, depositadas sobre as antigas após estas terem sido erodidas. Hutton foi o primeiro a reconhecer e interpretar a importância das discordâncias e o seu testemunho de um tempo geológico profundo. Ele escreve: 
"Está claro que os xistos foram endurecidos, elevados, quebrados, e gastos pelo atrito com a água, antes dos estratos secundários, que formam as partes mais férteis de nossas terras, existissem. É também certo que os topos das montanhas xistosas estiveram no fundo dos oceanos no momento da formação dos estratos secundários" (Hutton 1788, p. 470-471).

Playfair traduziria poeticamente este sentimento nas seguintes palavras, quando levado pelo amigo até Siccar Point: "A mente pareceu rodopiante ao olhar tão fundo para o abismo do tempo...".

Percebe-se que o movimento romântico e a sua influência na literatura, nas artes e na poesia teve também um fator de influência no desenvolvimento da geologia como uma ciência que abriu os olhos do ser humano para a natureza e a história natural (p. ex. Nicolson 1959). Existia de fato uma espécie de glamour romântico nos esforços de campo dos primeiros geólogos, os chamados "cavaleiros do martelo" (Tomkeieff 1949), que tendia a interpretar a natureza não apenas como um sistema ecológico finamente ajustado para sustentar a vida humana sobre o planeta, mas também como fonte de estímulo intelectual, prazer estético e felicidade. Neste sentido é interessante traçar os ecos da Analítica do Sublime como definido por Burke e Kant no sentimento de pequenez ante a imensidão do tempo geológico e dos processos naturais como traduzido por Hutton e Playfair. Nota-se, no texto de Hutton, uma tensão fundamental entre os enormes poderes e forças da natureza, a imensidão do tempo geológico, e o papel de manter as condições de vida de uma espécie humana que, individualmente, ocupará apenas uma ínfima parte deste tempo em vida no planeta, e será invariavelmente subjugada pelas enormes forças naturais em ação no ciclo geostrófico. Reconhecem-se então, dois tipos de sentimentos na teoria de Hutton que podem ser traduzidos em termos do Sublime Dinâmico e Matemático de Kant (1788), respectivamente, a sensação de impotência ante as forças da natureza e a sensação de pequenez da vida humana ante a imensidão do tempo geológico, como bem exemplificado por Playfair (1802).

A beleza benevolente de uma superfície terrestre feita para dar suporte à vida humana esconde, em suas profundezas, as terríveis forças de calor e pressão que são o seu motor; para Hutton, toda mudança na matéria não é nada mais do que o efeito da aplicação de terríveis forças naturais, e portanto, em termos Burkeanos, potencialmente sublimes.
Kant chamou este tipo de sentimento de Sublime Dinâmico, que aparece claramente na teoria de Hutton no seguinte parágrafo:

"Quando o fogo irrompe do fundo dos oceanos, e quando a terra é lançada acima e abaixo, com o poder de demolir cidades em um instante, e de fender rochas e montanhas sólidas, não há ninguém que não deva ver nisto um poder, que pode ser suficiente para concluir todas as visões da natureza no soerguimento da terra, como está situada nos lugares mais propícios para este fim (Hutton 1788, p. 271)".

De fato, percebe-se uma grande preocupação em Hutton sobre o efeito que suas palavras poderiam causar nos leitores, evocando primeiramente o prazer negativo relacionado ao sentimento de sublime:

\footnotetext{
"A elevação de um continente do fundo do mar é uma ideia grande demais para ser concebida facilmente em todas as partes de sua operação, muitas das quais talvez sejam desconhecidas para nós; e sem ser propriamente compreendida, uma ideia tão grande pode parecer imaginária. Da mesma forma, a operação correlativa ou correspondente, a destruição da terra, é uma ideia que não entra facilmente na mente humana em sua totalidade, apesar de diariamente ele testemunhar parte da operação" (Hutton 1788, p. 295).
}

Este é exatamente o gatilho do sentimento de sublime como definido por Kant, quando a mente é confrontada como uma ideia grande demais para a sua compreensão. Hutton não deseja, porém que seus leitores tenham as capacidades analíticas racionais inteiramente suspensas pela admiração perplexa das forças naturais. Ele introduz sabiamente a extensão do tempo geológico, por meio do qual os processos naturais são levados a cabo lentamente e de forma gradual, por meio de passos incrementais que seguem as leis naturais e que, portanto, podem ser cognoscíveis pela razão humana, desta forma estabelecendo a vitória do ser humano tanto moralmente quanto intelectualmente sobre o terrível sublime natural, exatamente como previsto por Kant.

Este aspecto da teoria de Hutton pode ser melhor compreendido se considerado o clima intelectual setecentista, que envolvia a busca por um padrão estrutural de correspondência entre o Macrocosmo (o Universo) e o Microcosmo (o Homem). A busca por este padrão estrutural ou "Sistema da Natureza" é a grande força motriz dos cientistas e filósofos do século XVIII, dentro dos ideais ilu- 
ministas, onde a natureza funcionaria por meio de relações causais compreensíveis pela aplicação da razão humana (Tomkeieff 1949). A salvação do ser humano por meio da razão moral ao ser confrontado com o sublime natural é apresentada por Hutton nas seguintes linhas:

O globo desta terra é evidentemente feito para o homem. Ele sozinho, de todos os seres que tem vida sobre este corpo, aproveita o todo e cada parte; ele sozinho é capaz de conhecer a natureza deste mundo, que ele então possui em virtude de seu direito próprio; e ele sozinho pode ter conhecimento deste sistema como uma fonte de prazer e um meio de felicidade" (Hutton 1788, p. 216-217).

Curiosamente, as tentativas de Hutton no sentido de evitar que seus leitores fossem paralisados pela sensação do Sublime Dinâmico da natureza, ao introduzir um conceito de mudança lenta e gradual, apenas introduz outra fonte de sensação do sublime, neste caso a do Sublime Matemático, ao confrontar o ser humano com as escalas de tempo infinitamente impensáveis para que os acréscimos infinitesimais nos eventos naturais pudessem produzir as feições da superfície terrestre.

\section{Além de Hutton: Influência no Romantismo Inglês}

Publicados logo após a Revolução Francesa, os escritos carregados de vitalismo materialista de Hutton levaram rapidamente a acusações de ateísmo, principalmente por sua visão de um tempo eternamente contínuo tanto para o passado, quanto para o futuro, o que parecia dispensar a necessidade de um criador que havia trazido toda a matéria à sua forma atual ex nihilo. O texto de Hutton em si parece oscilar continuamente entre a atribuição da beleza e complexidade dos sistemas naturais a um criador superior e à natureza em si própria. Esta visão da natureza como uma criadora benevolente e composta por inúmeros sistemas circulatórios e auto-reparadores como um organismo vivo, desenhada para sustentar a vida humana e ainda gerar prazer estético e intelectual, na verdade veio a antecipar a visão romântica da natureza que tomaria forma plenamente no decorrer do século XIX, principalmente dentre os poetas românticos ingleses como Coleridge e Wordsworth. Ambos tomaram conhecimento, aparentemente apenas superficial, das teorias de Hutton por meio de outro grande amigo e tradutor, Erasmus Darwin (Nicolson 1959,
Heringman 2004, Furniss 2010).

As inter-relações entre o surgimento das Ciências da Terra, a experiência estética e a teoria do sublime no período romântico foram traçadas no trabalho de Marjorie Hope Nicolson "Mountain Gloom and Mountain Glory" (1959). Posteriormente, Heringman (2004), em seu livro "Romantic Rocks, Aesthetic Geology", sugere que a geologia e a literatura romântica surgiram do mesmo ambiente cultural, que envolvia poesia, estética paisagística (p. ex. em Wordsworth), escritos de viagem (p. ex. de Saussure), dentre outros, culminando no termo "geologia estética". Tom Furniss, em artigo recente (2010), desenvolve a teoria de que as características estéticas dos escritos de Hutton permitem classificá-los como "Geologia Romântica". A leitura da questão a partir da literatura fornece uma visão da geologia estética como um ramo que surgiu da fusão de dois discursos separados: A literatura romântica e a geologia.

Infelizmente, talvez devido às acusações de ateísmo, o trabalho de Hutton não foi completamente apreciado e reconhecido por sua influência na geração de poetas românticos. Coleridge (apud Furniss 2010) escreve:

"Dr. Darwin se sentiria envergonhado em rejeitar a teoria da Terra de Hutton sem tê-la examinado minuciosamente; entretanto, o que significa para nós saber como a terra foi feita, uma coisa impossível de saber, e inútil se conhecida? Este sistema o doutor não rejeitou sem ter severamente o estudado; mas de repente ele se convence de tão importantes assuntos, como se nós somos os párias de uma idiota cega chamada Natureza, ou os filhos de um Deus onisciente e infinitamente bom" (tradução livre; apud Furniss 2010).

Na verdade, apesar do criticismo de Coleridge, pelos escritos de Hutton percebemos que a sua ideia central é a de uma natureza onipotente e infinitamente boa, uma ideia que impregnaria, por exemplo, os escritos de Wordsworth em sua fase mais fértil (Furniss 2010). De fato, paralelos à interpretação huttoniana do sentimento de Sublime na natureza podem ser encontrados por todo "O Prelúdio" de Wordsworth, como por exemplo, no Livro XIII, ao falar sobre a Natureza (tradução livre):

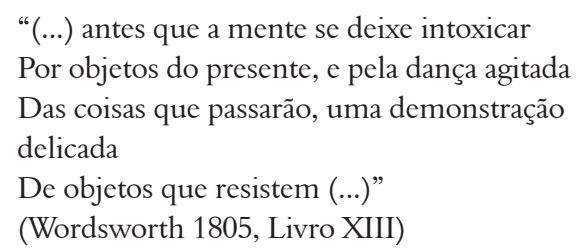




\section{Referências}

Aristóteles. 2007. Physics: book VIII. Trad. para inglês de Daniel W. Graham. Oxford: Clarendon Press, 232 p., re-edição 2007.

Baxter S. 2004. Revolutions in the Earth: James Hutton and the True Age of the World. Londres: Weidenfeld \& Nicolson Ltd, 245 p.

Craig G.Y. 1987. The 1785 Abstract of James Hutton's Theory of the Earth. Edimburgo: Edinburgh Univ. Library, $2^{a}$ ed. 1997. 42p.

Furniss T. 2010. A Romantic Geology: James Hutton's 1788 'Theory of the Earth'. Romanticism, 16(3):305321.

Gould S.J. 1991. Seta do Tempo, Ciclo do Tempo: Mito e metáfora na descoberta do tempo geológico. Trad. Carlos Afonso Malferrari. São Paulo: Cia. das Letras, 224 p.

Griggs E.L. ed. 1956. Collected Letters of Samuel Taylor Coleridge (6 v.). Oxford Scholarly Classics.

Heringman N. 2004. Romantic Rocks, Aesthetic Geology. Ithaca: Cornell Univ. Press. 304p.

Hume D. 1777. Enquiries Concerning Human Understanding and Concerning the Principles of Morals. 2 ed. 1902. Oxford: Clarendon Press. 458p.

Hutton J. 1749. Dissertatio Physico-Medica Inauguralis de Sanguine et Circulatione Microcosmi. Leiden. 34p.

Hutton J. 1788. Theory of the Earth; or an investigation of the laws observable in the composition, dissolution, and restoration of land upon the Globe. Trans. Royal Society of Edinburgh, 1:209-304.

Hutton J. 1795. Theory of the Earth, with Proofs and Illustrations. 2 v., Edinburgh and London.
Kant I. 1788. Crítica da Faculdade do Juízo. Trad. Valério Rohden \& Antônio Marques. Ed. Forense Univ., 1993, 384 p.

Lyell C. 1832. Principles of Geology. Londres: Penguin Classics, 1998 (abridged version).

Lucrécio. 2015. Da Natureza das Coisas. Tradução de Luis Manoel Gaspar Cerqueira. Lisboa: Relógio D’água, re-edição. 406 p.

Montgomery D.R. A crença no Dilúvio: campo e teoria na evolução da paisagem antes da geomorfologia. Terre Didatica, 13(1):44-62. URL: http://www.ige.unicamp. br/terraedidatica/v13 1/PDF13 1/TD131-3.pdf. Acesso 26.09 .2017 .

Nicolson M.H. 1959. Mountain Gloom and Mountain Glory: The Development of the Aesthetics of the Infinity. Washington: Univ. Washington Press, $432 \mathrm{p}$.

Playfair J. 1802. Illustrations of the Huttonian Theory of the Earth. Cambridge Univ. Press, re-edição 2011. 554 p.

Piper H.W. 1962. The Active Universe: Pantheism and the Concept of Imagination in the English Romantic Poets. London: Bloomsbury Academic, 243 p.

Porter R. 1977. The Making of Geology: Earth Science in Britain, 1660-1815. Cambridge University Press, 300 p.

Steno N. 1669. De solido intra solidum naturaliter contento dissertationis prodromus. Florença.

Tomkeieff S.I. 1949. XVII. James Hutton and the Philosophy of Geology. Proceedings of the Royal Society of Edinburgh. Section B. Biology, 63(4):387-400.

Ussher J. 1658. The Annals of the World. 7 ed., Green Forest (EUA): Master Books, re-edição 2007. 960p.

Wordsworth W. 1805. The Prelude: Or, Growth of a Poet's Mind. Oxford: Oxford Univ. Press, 1970, 368 p.

Resumo: 0 trabalho do geólogo, naturalista e médico escocês James Hutton [1726-1797], no contexto do lluminismo Escocês, sofreu grande influência das ideias de pensadores como Isaac Newton e David Hume, representando uma síntese e uma transposição para as nascentes ciências geológicas da força motriz do pensamento iluminista da época. Sua visão da terível magnitude das forças naturais e da imensidão do tempo geológico perante a efemeridade da vida humana reflete os conceitos kantianos de Sublime Dinâmico e Matemático, respectivamente. A partir do desenvolvimento da Geologia como uma ciência que abriu os olhos humanos para a história natural, é possível traçar um paralelo entre as teorias de James Hutton e as visões sobre a natureza dos poetas românticos do século XIX, principalmente Coleridge e Wordsworth. Desta forma, a geologia nasce como ciência exatamente na encruzilhada entre dois dos maiores movimentos intelectuais e culturais da civilização ocidental, o lluminismo e o Romantismo.

Palavras-Chave: James Hutton, Teoria da Terra, lluminismo, Romantismo. 